\title{
A Comparative Assessment of Hydrogen Embrittlement: Palladium and Palladium-Silver (25 Weight\% Silver) Subjected to Hydrogen Absorption/Desorption Cycling
} \author{
Karim Rebeiz ${ }^{3}$, Steve Nesbit ${ }^{4}$, Andrew Craft ${ }^{*}$

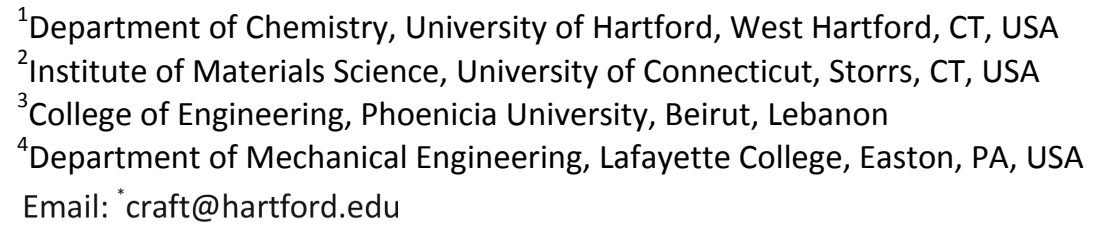

Gilberto Jimenez', Erik Dillon', Joseph Dahlmeyer', Travis Garrison', Tyler Garrison', Sedna Darkey1, Kyle Wald1, Joseph Kubik', Danielle Paciulli', Mustakim Talukder', Joshua Nott' ${ }^{1}$, Maria Ferrer ${ }^{1}$, Joseph Prinke ${ }^{1}$, Priscilla Villaneuva1, Fred Massicotte ${ }^{2}$,

Received 27 April 2016; accepted 27 June 2016; published 30 June 2016

Copyright (C) 2016 by authors and Scientific Research Publishing Inc.

This work is licensed under the Creative Commons Attribution International License (CC BY).

http://creativecommons.org/licenses/by/4.0/

C. (i) Open Access

\section{Abstract}

The negative effects of hydrogen embrittlement on metallic systems have been investigated through determination of the mechanical properties of two metallic systems that were exposed to hydrogen. An assessment of the effects of hydrogen absorption/desorption cycling on the tensile strength, ductility, and microhardness of pure palladium and the alloy palladium-silver $(25$ weight $\%$ silver) has been undertaken. The variables that are the focus of the study are the amount of hydrogen absorbed by the metal, deuterium isotope effect, number of hydrogen absorption/desorption cycles, and the hydrogen exposure temperature. Under all conditions studied, the mechanical properties of pure palladium were significantly altered as a result of hydrogen exposure, with significant hydrogen embrittlement occurring. In contrast, the mechanical properties of the palladium-silver alloy showed little alteration as a result of hydrogen exposure, including virtually no occurrence of hydrogen embrittlement.

"Corresponding author.

How to cite this paper: Jimenez, G., et al. (2016) A Comparative Assessment of Hydrogen Embrittlement: Palladium and Palladium-Silver (25 Weight\% Silver) Subjected to Hydrogen Absorption/Desorption Cycling. Advances in Chemical Engineering and Science, 6, 246-261. http://dx.doi.org/10.4236/aces.2016.63025 


\section{Keywords}

\section{Hydrogen, Palladium, Palladium-Silver, Embrittlement}

\section{Introduction}

Though naturally-occurring elemental hydrogen is virtually non-existent on our planet, hydrogen finds its way, either through natural or synthetic pathways, into the make-up of many types of chemical compounds. There are ionic hydrides (e.g. potassium hydride), covalent hydrides (e.g. ammonia), polymeric hydrides (e.g. beryllium hydride) and metallic hydrides (e.g. niobium hydride). Among the metallic hydrides, transition metal-hydrogen (M-H) systems are extraordinarily interesting systems of study in various areas of science, engineering and technology. M-H systems are composed of a transition metal (or alloy) matrix and atomic hydrogen occupying interstitial sites within the metallic lattice; the system will form non-stoichiometric solid solutions of atomic hydrogen in the metallic lattice. The most common methods of forming $\mathrm{M}-\mathrm{H}$ systems are through the exposure of the metal to hydrogen gas or by electrochemical means. The influence of hydrogen absorption and desorption on many important properties of such systems has been the focus of many fundamental studies into solid-gas systems for decades. There have been investigations focused on the thermodynamic properties of these materials [1], electrical properties [2], optical properties [3], structural properties [4], phase stability properties [5] and mechanical properties [6]. These materials are at the center of truly multidisciplinary investigations and are studied by chemists, physicists, engineers, materials scientists and metallurgists.

In addition to providing interesting model systems for fundamental multidisciplinary studies on the characteristics of solid-gas systems, $\mathrm{M}-\mathrm{H}$ materials have practical applications, some potential and some currently realized. Batteries based on M-H materials have been on the market for a number of years. M-H systems have been studied extensively for their potential use as media for the safe storage of combustible hydrogen in transportation applications [7]. M-H materials also have been looked at as possible non-mechanical refrigeration and heat pump systems owing to the exothermicity and endothermicity of the hydrogen absorption and desorption processes, respectively [8]. Also, $\mathrm{M}-\mathrm{H}$ materials currently do play a very important role in the purification of hydrogen from its natural impure sources (e.g. generation of pure hydrogen gas from hydrocarbon sources) [9].

A nagging issue associated with the potential uses of $\mathrm{M}-\mathrm{H}$ materials has to do with a problem that has been recognized since the earliest studies on these materials-hydrogen embrittlement. Unfortunately, the absorption and the desorption of hydrogen by metallic materials are very often accompanied to varying degrees by the occurrence of undesirable brittleness in the metallic matrix [10]. In many M-H systems, hydrogen embrittlement results in severe loss of ductility in the metal matrix. This has been an issue in the steel industry, the nuclear industry, various manufacturing industries, as well as in the aforementioned hydrogen storage, refrigeration/heat pump, and purification applications of M-H materials.

Of the many transition metal-hydrogen systems, one of the most studied has been the palladium hydrogen (Pd-H) system. Palladium has been an attractive metal to study within the context of M-H systems owing to the non-extreme conditions under which it readily absorbs hydrogen and the ability of palladium to retain its hydrogen absorbing properties in the presence of impurity gases that often poison the surface of other metals to hydrogen absorption [11]. Though well-suited to being a model system for fundamental studies on M-H systems, the Pd-H system does suffer from the deleterious effects of hydrogen embrittlement and this limits the uses of palladium in many potential applications of M-H systems [12].

Though not quite as well studied as the $\mathrm{Pd}-\mathrm{H}$ system, the palladium-silver $(\mathrm{Pd} / \mathrm{Ag})$ alloy system has received a great deal of attention both as a model system to study the effects that alloying has on the hydrogen absorbing properties of palladium and for its possible uses in several areas of hydrogen-based technology. Prominent among these uses is as hydrogen purification materials [13]. Like pure palladium, Pd/Ag materials are virtually $100 \%$ selective to the absorption of hydrogen from a mixture of gases, making these alloys ideal for separating hydrogen from such a mixture. From several perspectives, Pd/Ag materials enjoy superior performance compared to pure palladium as hydrogen purification materials and in other potential applications of M-H systems. $\mathrm{Pd} / \mathrm{Ag}$ materials have superior hydrogen transport properties than pure palladium [13]. Pd/Ag materials have more stable mechanical properties in the presence of hydrogen compared to pure palladium, including a reduc- 
tion in hydrogen embrittlement [13]. Because of these enhancements over pure palladium, Pd/Ag materials currently are the most common materials used for hydrogen purification/separation applications.

In many studies on $\mathrm{M}-\mathrm{H}$ materials (including those on $\mathrm{Pd} / \mathrm{Ag}$ alloys), the occurrence of hydrogen embrittlement is typically acknowledged but not investigated quantitatively. Since hydrogen embrittlement is such a cause for concern in many environments where metals interact with hydrogen, the need to better understand the conditions that result in embrittlement and the degree to which embrittlement occurs is critical. Several of the authors of the present manuscript have been involved in several investigations that have focused on the effects of hydrogen exposure on the mechanical properties of palladium and palladium-based alloy systems [6] [14]. This paper builds upon those earlier studies and seeks to provide an insight into the conditions that result in hydrogen embrittlement and, hopefully, conditions that may mitigate the occurrence of hydrogen embrittlement. Toward that end, we report the results of a comprehensive comparative quantitative study on the effects that various facets of hydrogen absorption and desorption have on the strength, ductility and hardness of pure palladium and the palladium-silver (25 weight\%) alloy.

\section{Experimental}

Palladium (99.9\% total purity) foil (Alfa-Aesar, Ward Hill, MA, USA) and palladium:silver, 75:25 wt\% (99.9\% pure basis metal) foil (ACI Alloys, San Jose, CA, USA) of $0.25 \mathrm{~mm}$ thickness were used in this study. These foils were unidirectionally cut into 38.1-mm-long by 6.4-mm-wide specimens. A reduced section of $3.2 \mathrm{~mm}$ width was machined into each specimen that was used for tensile testing. Specimens were lightly abraded with fine emery paper, then chemically polished in a 2:2:1 volume mixture of $\mathrm{H}_{2} \mathrm{SO}_{4}: \mathrm{HNO}_{3}: \mathrm{H}_{2} \mathrm{O}$, followed by liberal rinsing, in an ultrasonic cleaner, with distilled water and then acetone. All specimens were then stress relieved in vacuo at $723 \mathrm{~K}$ for $48 \mathrm{~h}$, followed by a $24 \mathrm{~h}$ annealing in vacuo at $823 \mathrm{~K}$. These annealing temperatures were high enough to allow recovery of each specimen to a nearly defect-free state.

Hydrogen absorption/desorption by the annealed specimens was carried out in an all-stainless steel system of calibrated volumes. The temperature of the specimen chamber of the system was maintained by either a regulated water bath or furnace. Hydrogen gas pressures were measured with MKS diaphragm gauges and the hydrogen content of the specimens was determined by means of the Ideal Gas Law from changes in the hydrogen gas pressure. The hydrogen content was calculated and reported as the hydrogen-to-palladium ratio $(\mathrm{H} / \mathrm{Pd})$ or hydrogen-to-Pd/Ag (25 wt\%) ratio (H/alloy). Where noted, upon reaching hydrogen saturation or a desired hydrogen content during hydrogen absorption, specimens were evacuated for $24 \mathrm{~h}$ to remove all absorbed hydrogen. The evacuation was carried out via a vacuum system composed of a HyVac two-stage pump (HyVac Products, Pottstown, PA, USA). More details of specific absorption/desorption cycling treatments are given in appropriate portions of the Results section of the paper.

Following each hydrogen exposure treatment on the specimens, tensile tests were carried out using an Instron Series IX Automated Materials Testing System (Instron Corporation, Norwood, MA, USA) using a constant elongation rate of $1.27 \mathrm{~mm} / \mathrm{min}$. Specimens used for microhardness testing were subjected to a series of polishings culminating in a 0.05 micron alumina polishing. Vickers microhardness tests were performed on a LECO Microhardness Tester (LECO Corporation, St. Joseph, MI, USA) using a load of $100 \mathrm{~g}$.

\section{Results}

Figure 1 shows a representative engineering stress-strain curve from the present study. This particular stressstrain curve is for vacuum annealed Pd/Ag ( $25 \mathrm{wt} \%)$. Such stress-strain curves were used to determine values of ultimate strength, yield strength, and total elongation. The ultimate strength is the maximum stress that a material can withstand prior to failure. The yield strength is the stress at which a material begins to exhibit significant plastic (i.e. permanent) deformation. Total elongation is the percent elongation at the point of failure and is the characteristic most reflective of hydrogen embrittlement. The more brittle a substance is, typically the less is the elongation at failure.

\subsection{Mechanical Properties of Vacuum-Annealed Materials}

Before considering any effects that hydrogen exposure may have on the mechanical properties of pure Pd and $\mathrm{Pd} / \mathrm{Ag}$ (25 wt\%), it will be fruitful to establish baseline values for these properties via a comparison of the me- 
chanical properties of well-annealed Pd with well-annealed Pd/Ag (25 wt\%) that have not been exposed to hydrogen. The values for yield strength, ultimate strength, total elongation (elongation at failure), and microhardness are given in Table 1 for both well-annealed materials.

As can be seen from the values in the table, the alloying of silver with palladium caused significant solid solution strengthening. Such solid solution strengthening has been observed during other investigations on the $\mathrm{Pd} / \mathrm{Ag}$ (25 wt\%) alloy [15] [16]. The current results show superior strength and hardness characteristics in the annealed $\mathrm{Pd} / \mathrm{Ag}$ alloy as compared to annealed palladium, with these properties experiencing essentially a doubling in value due to the alloying of silver with palladium. The ultimate and yield strengths of the annealed Pd/Ag alloy found in the current study are slightly lower than the values found by Timofeev et al. [15] while the hardness values of the annealed alloy found in the current study are consistent with the values found by Tosti et al. [16]. Unfortunately, the alloying of silver with palladium resulted in no enhancement in ductility (elongation), which would be desirable in many applications. This finding contrasts with the finding of Timofeev et al. who found a nearly 50\% increase in elongation of well annealed Pd/Ag (25 wt\%) as compared to well-annealed Pd [15].

\subsection{Varying the Amount of Hydrogen Absorbed}

In this study, samples of annealed palladium foil were dosed with the protium isotope $\left({ }^{1} \mathrm{H}\right)$ of hydrogen to $\mathrm{H} / \mathrm{Pd}$ atom ratios of $0.02,0.20,0.35,0.49,0.66$, and 0.72 , respectively. Upon reaching the respective H/Pd ratio, samples were evacuated for $24 \mathrm{~h}$ to remove the absorbed hydrogen. All absorption/desorption cycling in this study was carried out at a constant temperature of $323 \mathrm{~K}$. Similar $323 \mathrm{~K}$ hydrogen dosing was carried out on $\mathrm{Pd} / \mathrm{Ag}$ (25 wt\%) except that the H/alloy ratios reached were 0.10, 0.15, 0.20, 0.30 and 0.35 .

Figure 2 shows the ultimate tensile strengths of palladium and $\mathrm{Pd} / \mathrm{Ag}$ (25 wt\%) as functions of the final H/Pd or H/alloy reached during the absorption segment of the cycling treatment. Figure 3 shows the yield strengths of palladium and $\mathrm{Pd} / \mathrm{Ag}$ (25 wt\%) as functions of the final H/Pd or H/alloy reached during the absorption segment of the cycling treatment. Figure 4 shows the total elongations (i.e. elongation at failure) of palladium and $\mathrm{Pd} / \mathrm{Ag}$ (25 wt\%) as functions of the final H/Pd or H/alloy reached during the absorption segment of the cycling treatment. In these figures, results corresponding to $\mathrm{H} / \mathrm{Pd}=0$ and $\mathrm{H} /$ alloy $=0$ refer to palladium and $\mathrm{Pd} / \mathrm{Ag}(25 \mathrm{wt} \%)$ that were annealed in vacuo as described in the experimental section and not subsequently exposed to hydrogen. As these figures clearly illustrate, in many instances the tensile properties of Pd are quite sensitive to the final

Table 1. Mechanical properties of well-annealed palladium and palladium-silver (25 wt\%) alloy.

\begin{tabular}{ccc}
\hline Mechanical property & Well-annealed Pd & Well-annealed Pd/Ag (25\%) \\
\hline Ultimate strength (MPa) & 150 & 274 \\
Yield strength (MPa) & 60 & 20 \\
Total elongation (\%) & 21 & 113 \\
Vickers microhardness (VHN) & 65 & 24 \\
\hline
\end{tabular}

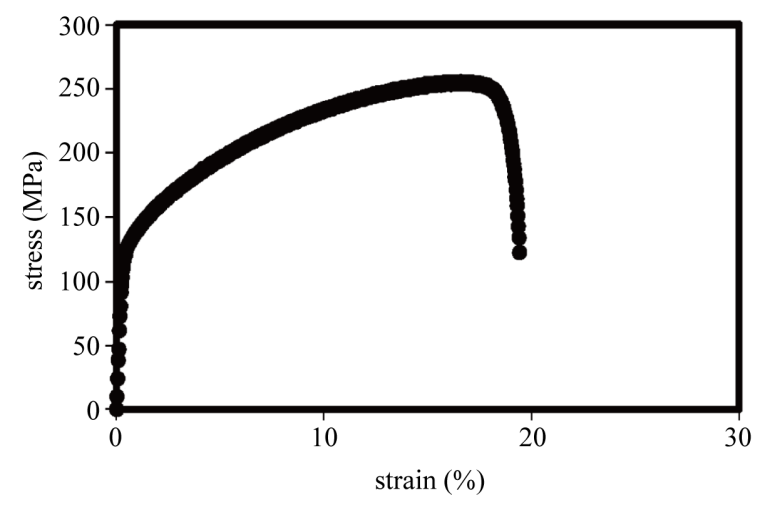

Figure 1. Representative engineering stress-strain curve (vacuum annealed Pd/Ag (25 wt\%)). 


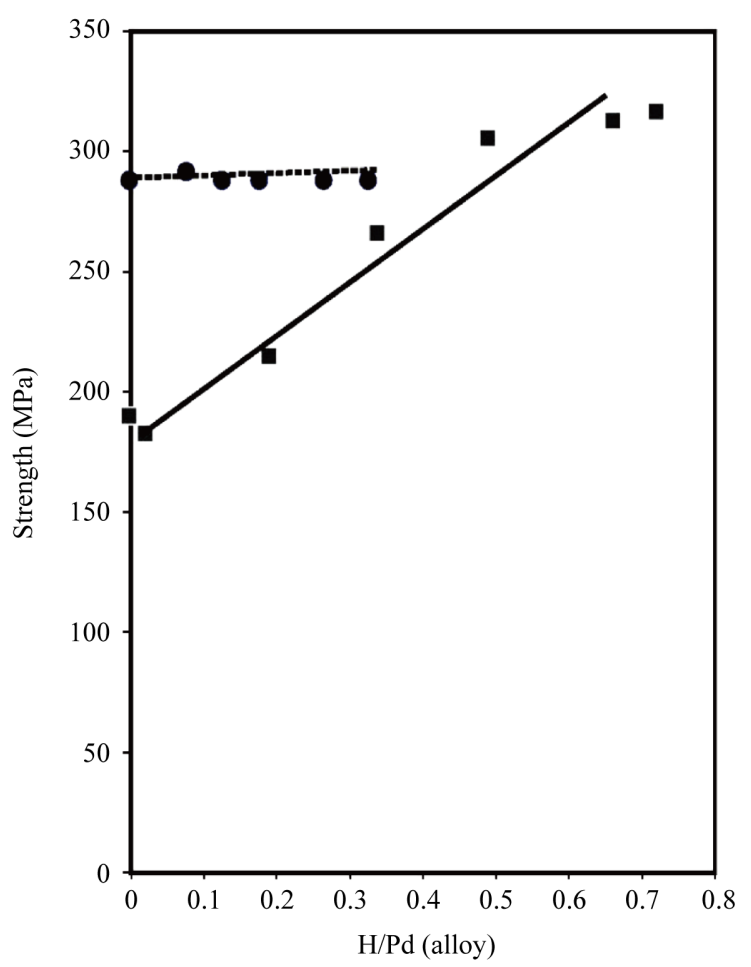

Figure 2. Ultimate strength of palladium ( $\mathbf{m})$ and $\mathrm{Pd} / \mathrm{Ag}$ $(25 \mathrm{wt} \%)(\bullet)$ as a function of final H/Pd (alloy) reached during absorption segment of cycling treatment.

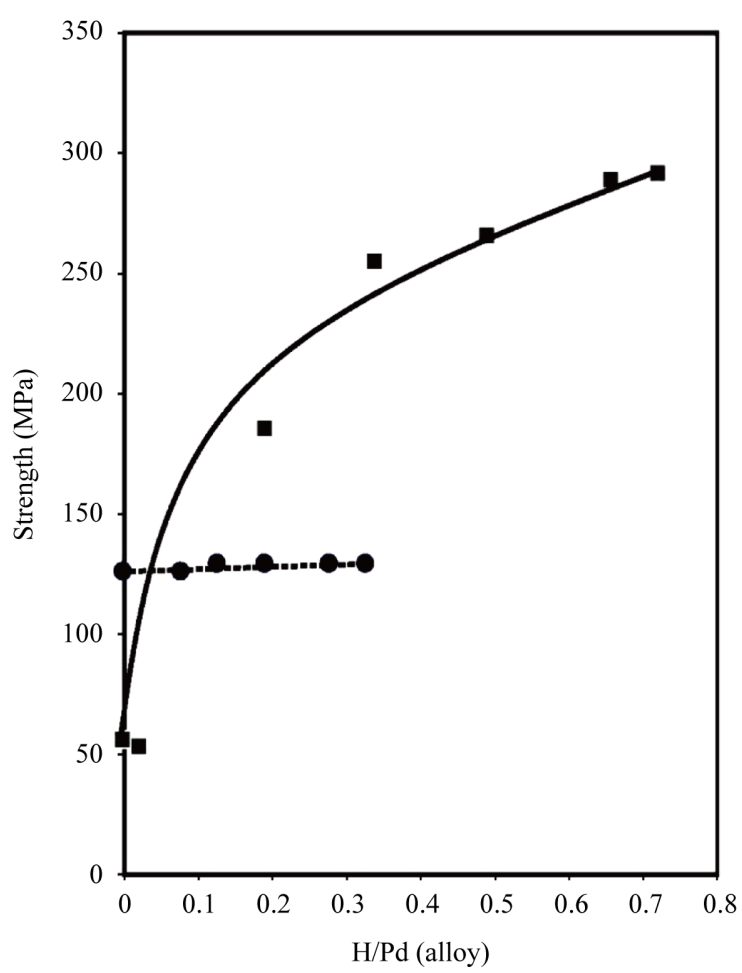

Figure 3. Yield strength of palladium ( $\mathbf{\square})$ and $\mathrm{Pd} / \mathrm{Ag}(25$ $\mathrm{wt} \%)(\bullet)$ as a function of final $\mathrm{H} / \mathrm{Pd}$ (alloy) reached during absorption segment of cycling treatment. 


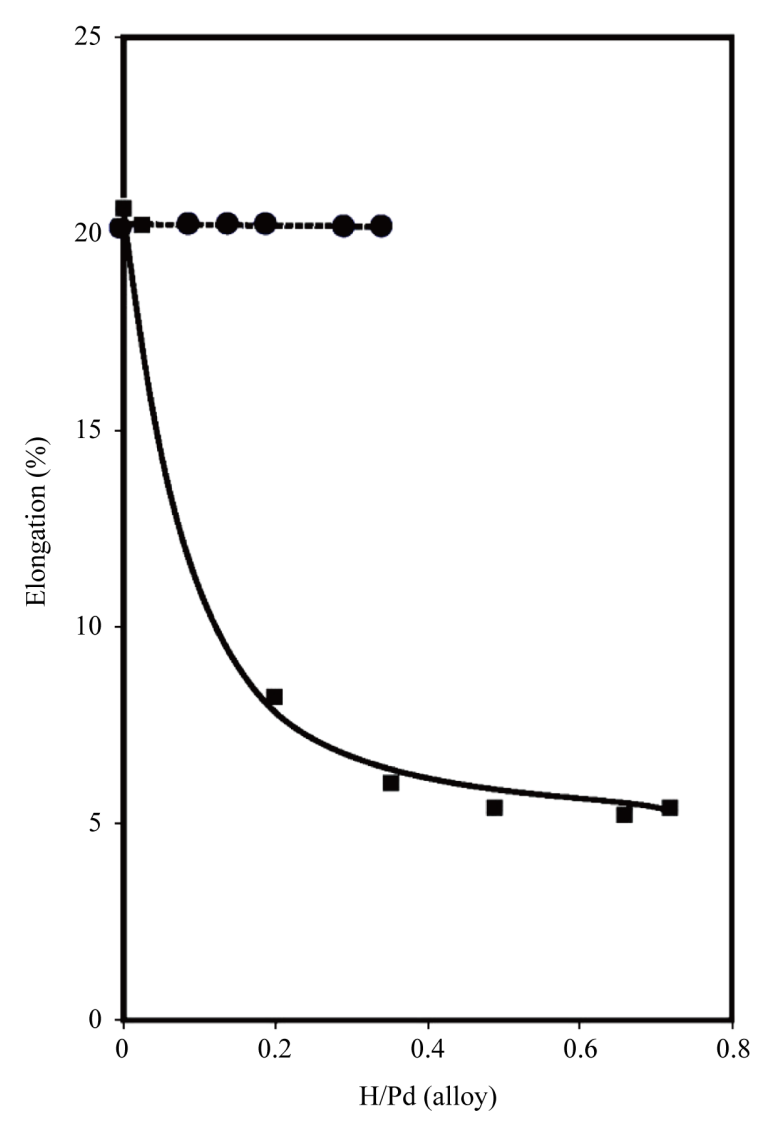

Figure 4. Total elongation of palladium ( $\mathbf{\square})$ and $\mathrm{Pd} / \mathrm{Ag}$ $(25 \mathrm{wt} \%)(\bullet)$ as a function of final H/Pd (alloy) reached during absorption segment of cycling treatment.

hydrogen content reached during the absorption segment of the cycling treatment. In most cases, as the final hydrogen content reached during absorption increases, the strength of palladium increases and the ductility (elongation) decreased. In contrast, the strength and the ductility of Pd/Ag (25 wt\%) show virtually no effects of hydrogen absorption/desorption, regardless of the final hydrogen content reached during hydrogen absorption. The strength and ductility of $\mathrm{Pd} / \mathrm{Ag}$ ( $25 \mathrm{wt} \%$ ) show no significant variations from the values of the vacuum-annealed alloy.

Vickers microhardness as functions of the final $\mathrm{H} / \mathrm{Pd}$ or H/alloy ratio reached during the absorption segment of the cycling treatment is shown in Figure 5. As with the strength and elongation results, the hardness values corresponding to $\mathrm{H} / \mathrm{Pd}=0$ and $\mathrm{H} /$ alloy $=0$ refers to palladium and $\mathrm{Pd} / \mathrm{Ag}(25 \mathrm{wt} \%)$ that were annealed in vacuo as described in the experimental section and not subsequently exposed to hydrogen. As can be seen, in most cases the hardness of palladium, like the strength, increases as the final hydrogen content reached during absorption increases while the hardness of the Pd/Ag alloy remains virtually unchanged from its well annealed value.

When considering Figures 2-5, it is important to remember that, although hydrogen content is reported as a variable, all specimens were hydrogen-free during testing. The H/Pd and H/alloy values refer to the hydrogen content reached during the absorption segment of the absorption/desorption cycling treatment; all absorbed hydrogen was removed from each specimen prior to testing.

\subsection{Varying the Amount of Deuterium Absorbed}

This study sought to identify any isotope effects that might exist in the work carried out in the previous investigation reported in section 3.2. Toward that end, samples of annealed palladium and $\mathrm{Pd} / \mathrm{Ag}$ (25 wt\%) foils were dosed with the deuterium isotope $\left({ }^{2} \mathrm{H}\right)$ of hydrogen to D/Pd and D/alloy atom ratios identical to those in section 3.2. Upon reaching the respective $\mathrm{D} / \mathrm{Pd}$ and D/alloy ratio, samples were evacuated for $24 \mathrm{~h}$ to remove the 


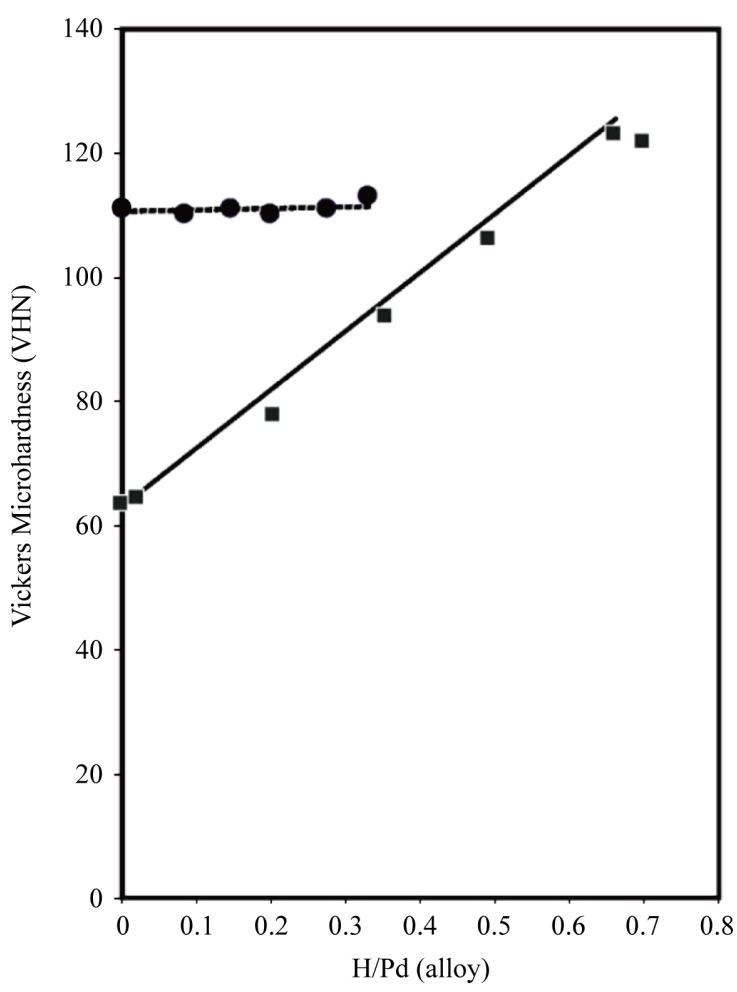

Figure 5. Vickers microhardness of palladium ( $\mathbf{a})$ and $\mathrm{Pd} / \mathrm{Ag}(25 \mathrm{wt} \%)(\bullet)$ as a function of final H/Pd (alloy) reached during absorption segment of cycling treatment.

absorbed deuterium. All absorption/desorption cycling in this study was, like those in section 3.2, carried out at a constant temperature of $323 \mathrm{~K}$.

Figures 6-9 show the ultimate strength, yield strength, total elongation, and Vickers microhardness, respectively, as functions of the final D/Pd or D/alloy ratio reached during the absorption segment of the cycling treatment. Similar to the results for protium (see section 3.2), results corresponding to $\mathrm{D} / \mathrm{Pd}=0$ and $\mathrm{D} / \mathrm{alloy}=0$ refer to specimens that were annealed in vacuo as described in the experimental section and not subsequently exposed to deuterium.

In general, the results for deuterium in palladium are similar to those found for protium in palladium. As the final deuterium content reached during absorption increases, the strength and hardness of the palladium matrix increases while the ductility decreases. In comparing the palladium results for protium (see section 3.2) with those for deuterium, it can be seen that the magnitude of the changes that manifest from deuterium cycling are slightly less than those caused by protium cycling. Similar to the studies done with protium, the mechanical properties of Pd/Ag (25 wt\%) remain remarkably unchanged as a result of deuterium absorption/desorption; the values of the measured parameters vary to no significant degree from those of the vacuum-annealed alloy.

\subsection{Varying Numbers of Complete Absorption/Desorption Cycles}

In this study, samples of annealed palladium and $\mathrm{Pd} / \mathrm{Ag}(25 \mathrm{wt} \%)$ foils were dosed with the protium isotope $\left({ }^{1} \mathrm{H}\right)$ of hydrogen to saturation at $323 \mathrm{~K}$. For Pd, saturation was considered to occur when the H/Pd exceeded 0.62 and for Pd/Ag (25 wt\%), saturation was considered to occur when the H/alloy exceeded 0.30 . Upon reaching saturation, samples were evacuated at $323 \mathrm{~K}$ for $24 \mathrm{~h}$ to remove the absorbed hydrogen. Respective specimens of palladium and $\mathrm{Pd} / \mathrm{Ag}$ (25 wt\%) were subjected to 1, 2, 3, 4, 5, and 10 complete absorption/desorption cycles at 323 K.

Figures 10-13 show the ultimate strength, yield strength, total elongation, and Vickers microhardness, respectively, as a function of number of complete absorption/desorption cycles experienced by well-annealed specimens. Values corresponding to zero cycles are for specimens that were annealed in vacuo as described in the 


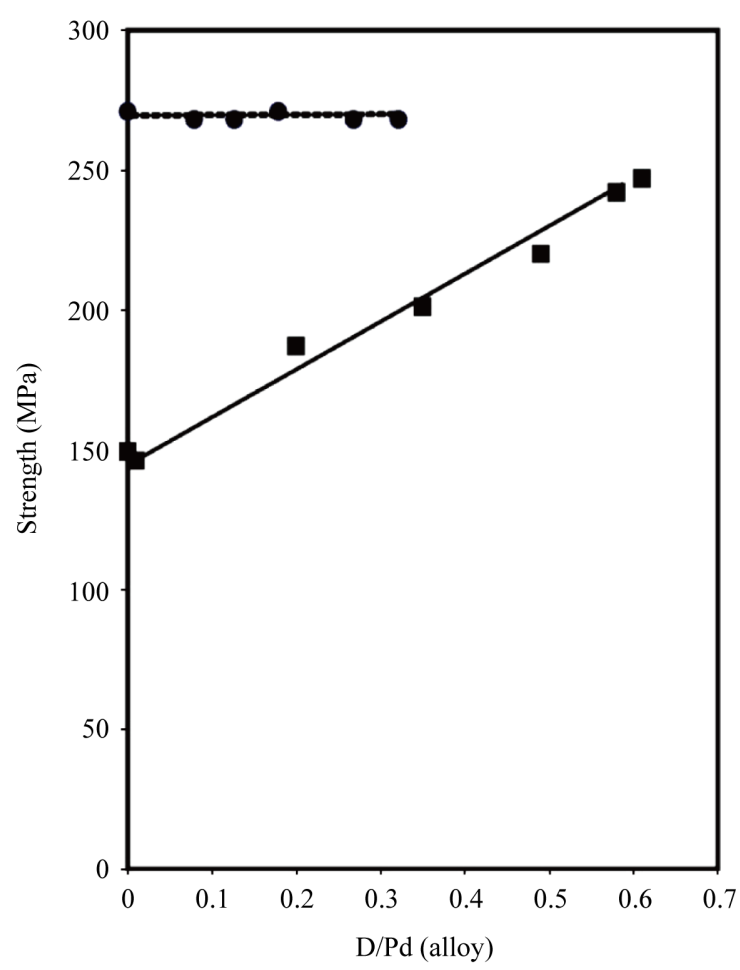

Figure 6. Ultimate strength of palladium ( $\mathbf{m})$ and $\mathrm{Pd} / \mathrm{Ag}$ $(25 \mathrm{wt} \%)(\bullet)$ as a function of final D/Pd (alloy) reached during absorption segment of cycling treatment.

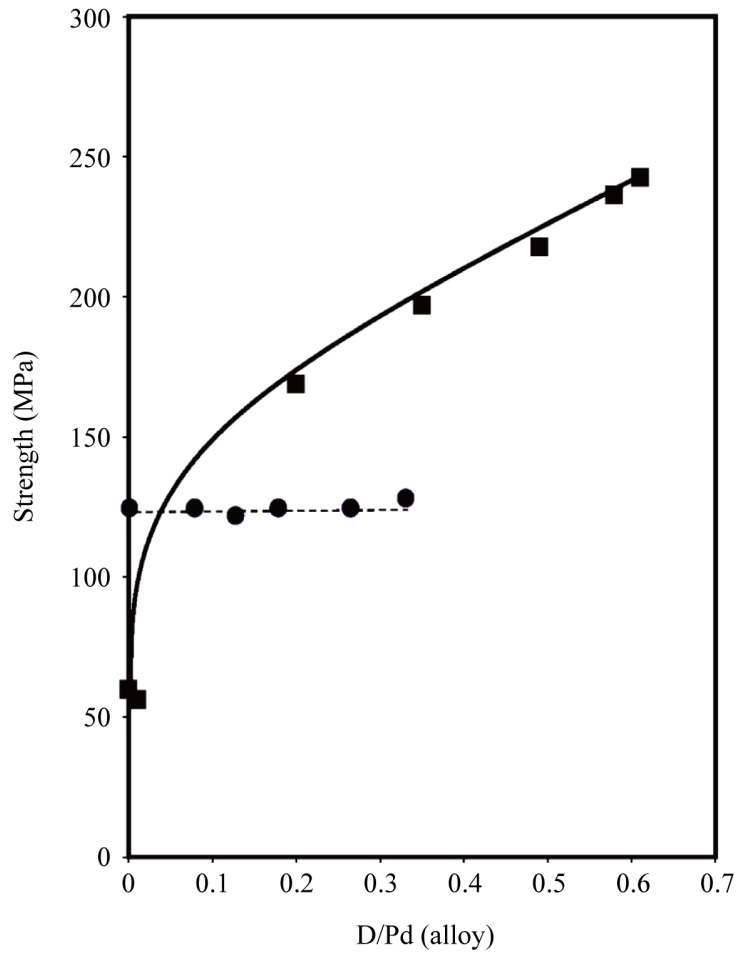

Figure 7. Yield strength of palladium ( $\bullet$ ) and $\mathrm{Pd} / \mathrm{Ag}(25$ $\mathrm{wt} \%)(\bullet)$ as a function of final D/Pd (alloy) reached during absorption segment of cycling treatment. 


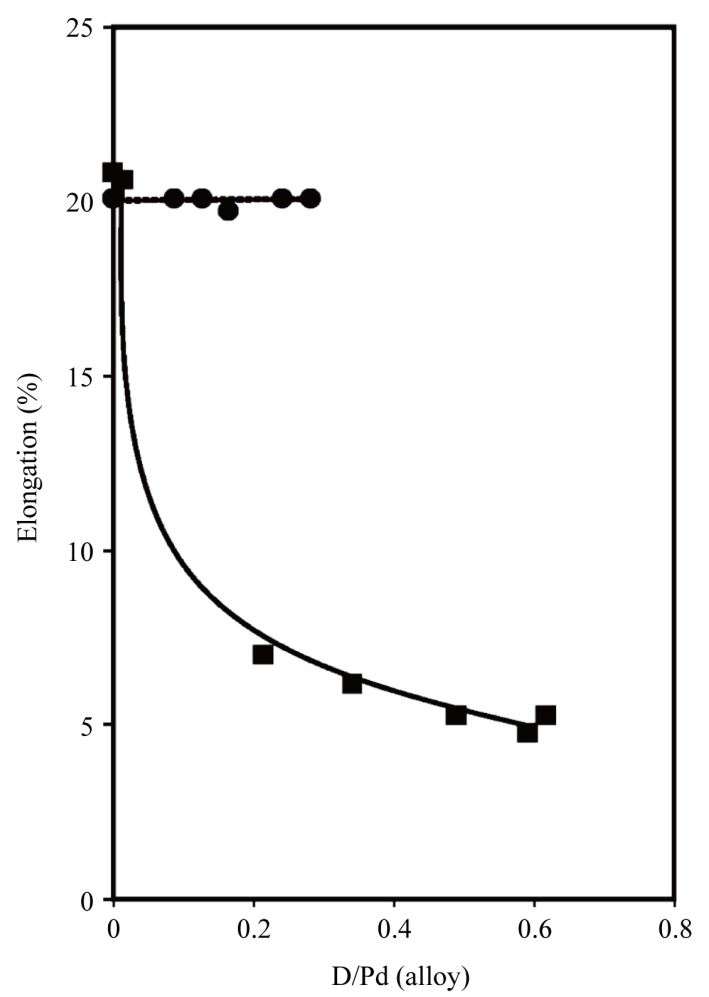

Figure 8. Total elongation of palladium ( $\mathbf{}$ ) and $\mathrm{Pd} / \mathrm{Ag}$ $(25 \mathrm{wt} \%)(\bullet)$ as a function of final D/Pd (alloy) reached during absorption segment of cycling treatment.

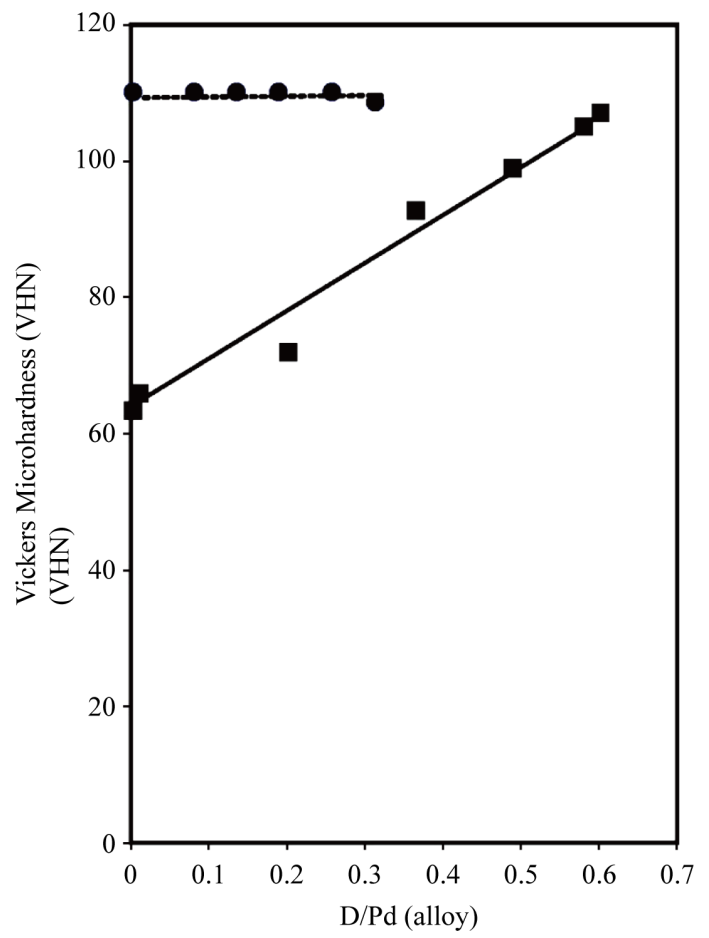

Figure 9. Vickers microhardness of palladium ( $\mathbf{a})$ and $\mathrm{Pd} / \mathrm{Ag}$ (25 wt\%) (alloy) reached during absorption segment of cycling treatment. 


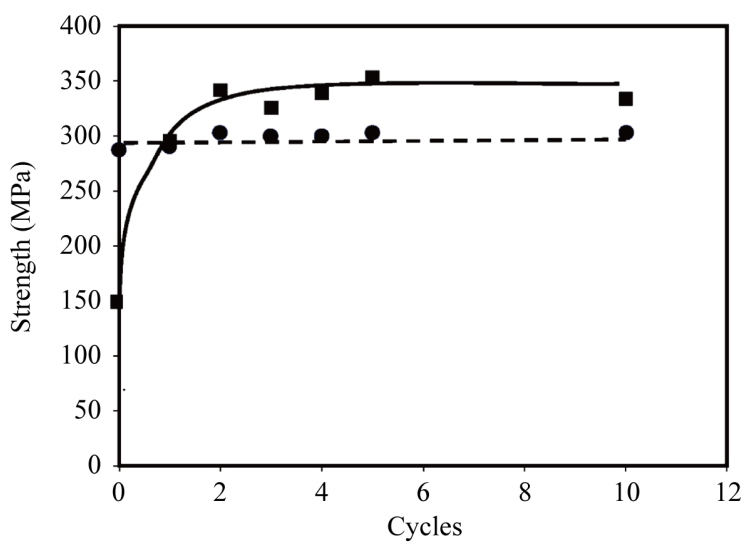

Figure 10. Ultimate strength of palladium (匹) and $\mathrm{Pd} / \mathrm{Ag}(25 \mathrm{wt} \%)(\bullet)$ as function of the number of absorption/ desorption cycles.

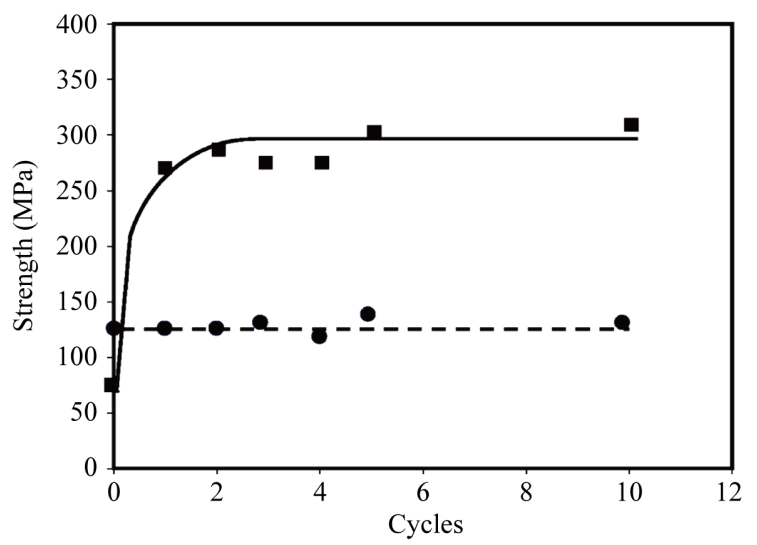

Figure 11. Yield strength of palladium ( $\bullet$ ) and $\mathrm{Pd} / \mathrm{Ag}(25 \mathrm{wt} \%)(\bullet)$ as function of the number of absorption/desorption cycles.

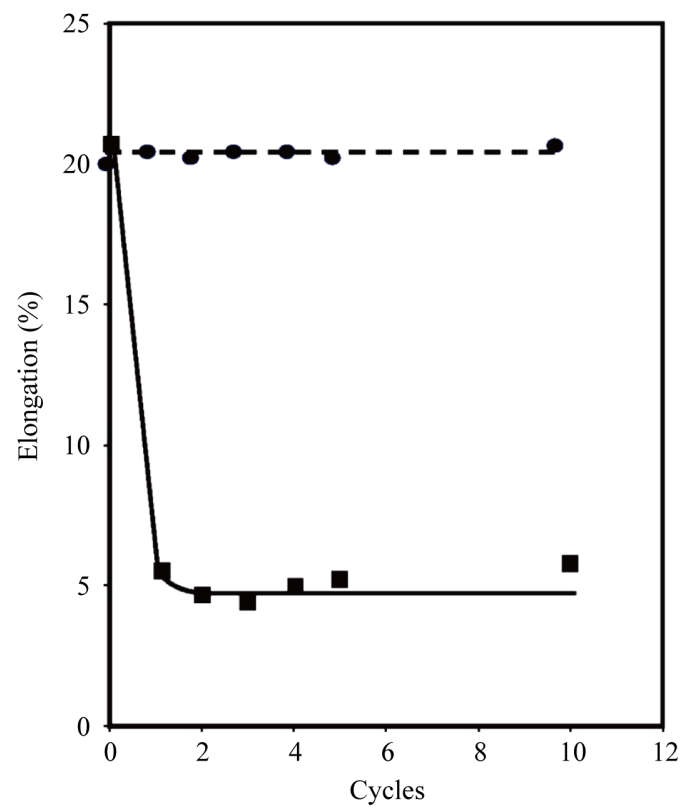

Figure 12. Total elongation of palladium (घ) and $\mathrm{Pd} / \mathrm{Ag}(25 \mathrm{wt} \%)(\bullet)$ as function of number of absorption/desorption cycles. 


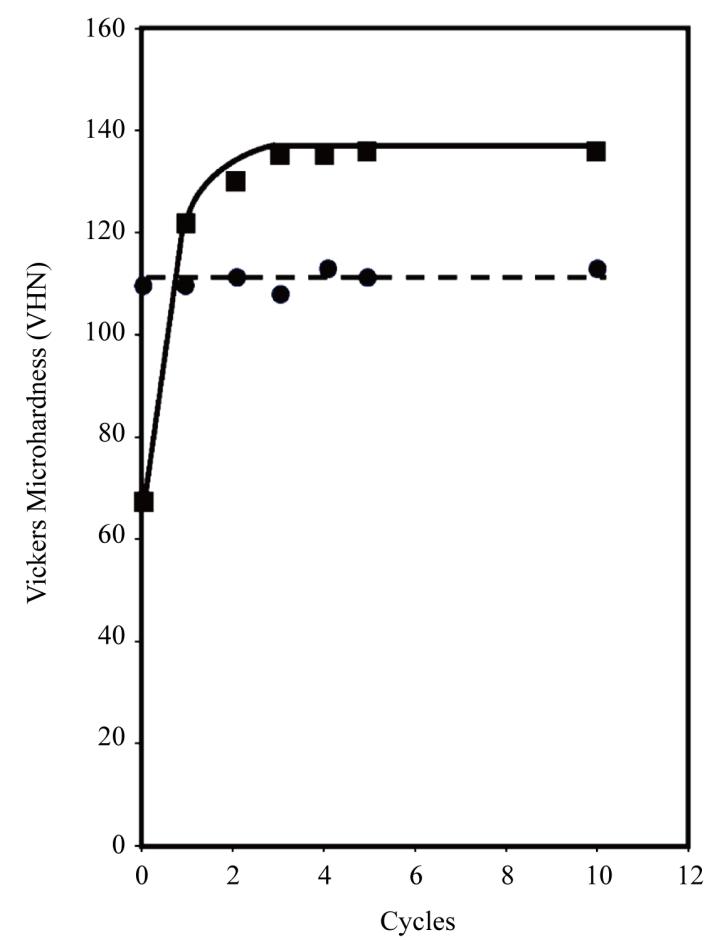

Figure 13. Vickers microhardness of palladium $(\mathbf{\square})$ and $\mathrm{Pd} / \mathrm{Ag}(25 \mathrm{wt} \%)(\bullet)$ as a function of number of absorption/desorption cycles.

experimental section and not subsequently exposed to hydrogen. As can be seen in all of these figures, the most significant changes in the mechanical properties of Pd result from the first cycle of hydrogen absorption/desorption. The first absorption/desorption cycle causes a precipitous increase in yield strength, ultimate strength, and hardness along with a precipitous decrease in ductility (elongation). There is a modest additional change to these properties due to the second complete absorption/desorption cycle but beyond the second cycle, the properties show very little additional change. In contrast, the results for Pd/Ag (25 wt\%) indicate that the mechanical properties of the alloy remain consistent with those of the vacuum annealed alloy regardless of the number of complete hydrogen absorption/desorption cycles experienced by the alloy.

\subsection{Varying the Temperature of the Complete Absorption/Desorption Cycle}

Similar to the samples in part (iv), in this study, samples of annealed palladium and Pd/Ag (25 wt\%) foils were dosed with the protium isotope $\left({ }^{1} \mathrm{H}\right)$ of hydrogen to saturation followed by complete desorption. In this study, a single complete isothermal cycle was carried out, on respective Pd specimens, at $50 \mathrm{~K}$ increments from $323 \mathrm{~K}$ to $523 \mathrm{~K}$ and at $25 \mathrm{~K}$ increments from $523 \mathrm{~K}$ to 623K. Respective specimens of Pd/Ag ( $25 \mathrm{wt} \%$ ) were subjected to isothermal saturation cycling at $10 \mathrm{~K}$ increments from $303 \mathrm{~K}$ to $353 \mathrm{~K}$ and at $25 \mathrm{~K}$ increments from $373 \mathrm{~K}$ to $473 \mathrm{~K}$. It is important to emphasize that although different cycling temperatures distinguish different sets of specimens, each individual cycling treatment on a specific set of specimens was carried out at constant temperature.

Figures 14-17 show the ultimate strength, yield strength, total elongation, and Vickers microhardness, respectively, as a function of the hydrogen absorption/desorption cycling temperature experienced by well-annealed specimens. As can be seen in the figures, the mechanical properties of palladium are significantly affected by hydrogen absorption/desorption over the entire temperature range studied. Though temperature dependent, the strength and hardness of palladium increases due to cycling while the elongation decreases as a result of cycling. In general, as the cycling temperature increases, the degree of change to the mechanical properties of Pd decreases. Similar to the other reported investigations on $\mathrm{Pd} / \mathrm{Ag}$ (25 wt\%) in the present study, the mechanical properties of the cycled alloy specimens remain virtually unchanged from those of the vacuum annealed alloy, regardless of the hydrogen absorption/desorption temperature. 


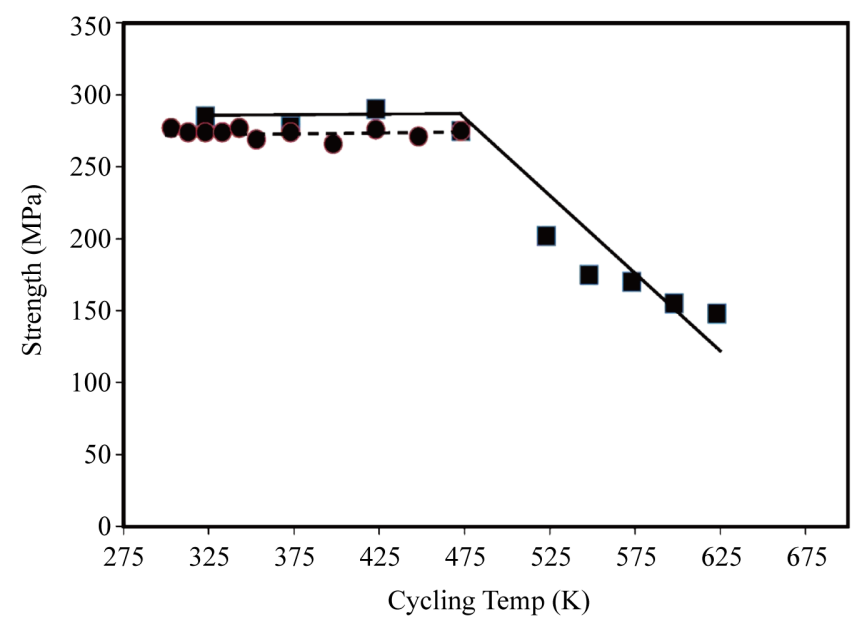

Figure 14. Ultimate strength of palladium ( $\square$ ) and $\mathrm{Pd} / \mathrm{Ag}$ (25 wt\%) $(\bullet)$ as function of cycling temperature.

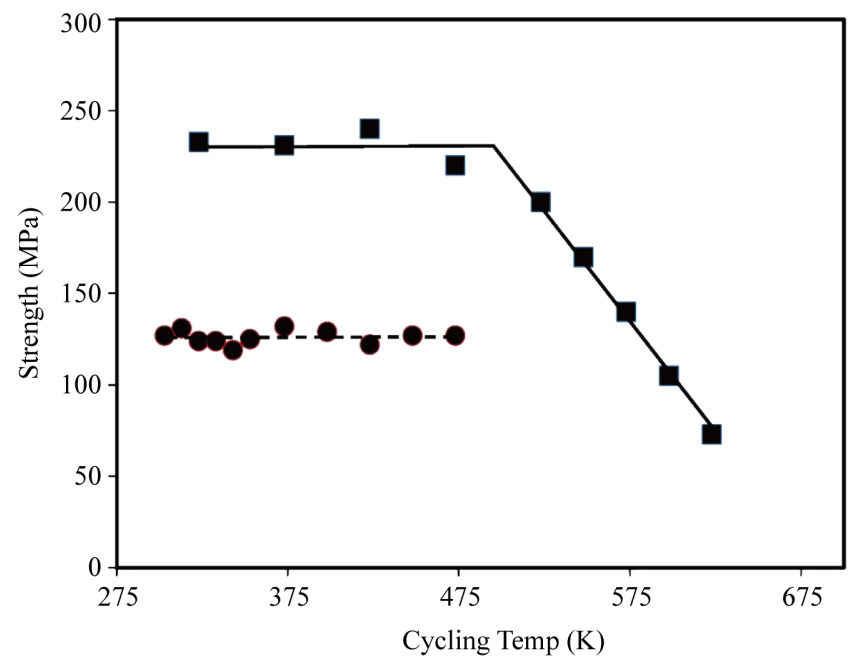

Figure 15. Yield strength of palladium (घ) and Pd/Ag (25 wt\%) $(\bullet)$ as function of cycling temperature.

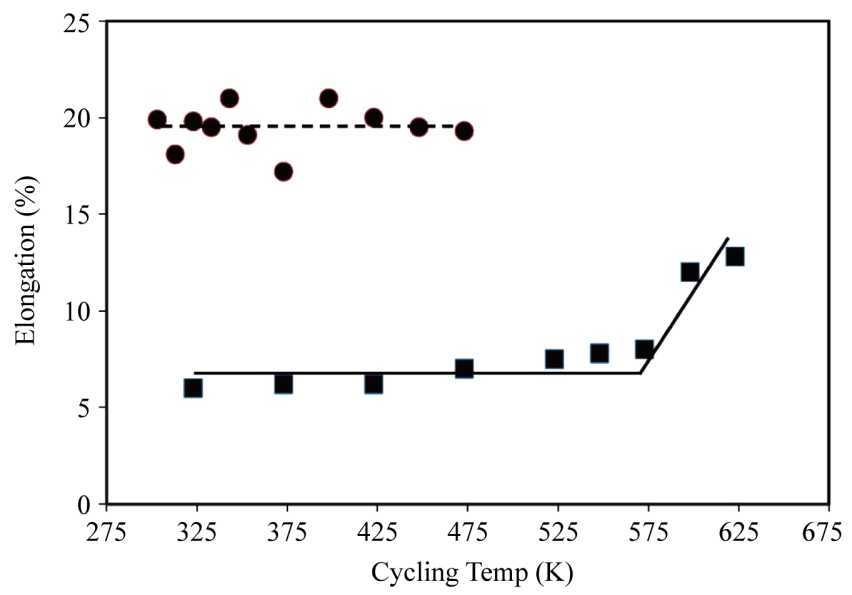

Figure 16. Total elongation of palladium (匹) and $\mathrm{Pd} / \mathrm{Ag}(25$ $\mathrm{wt} \%)(\bullet)$ as function of cycling temperature. 


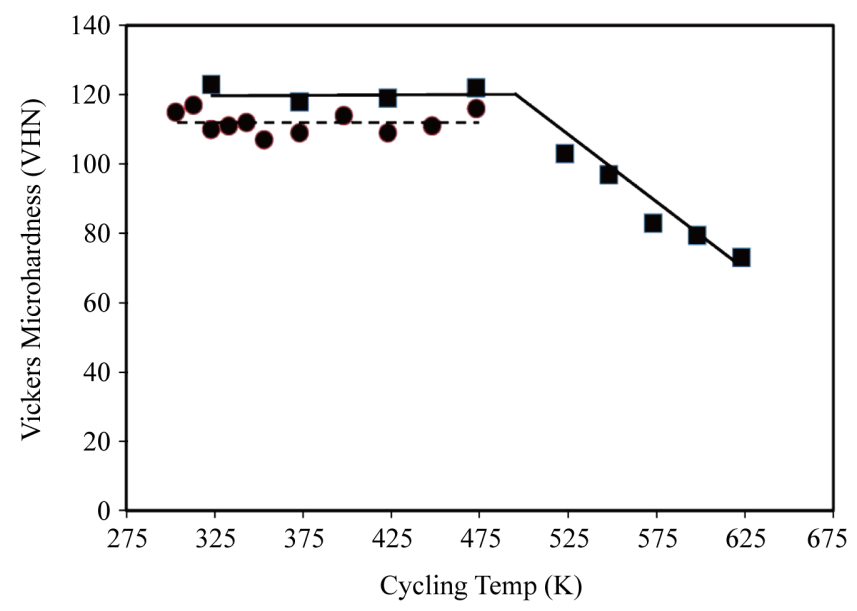

Figure 17. Vickers microhardness of palladium (匹) and $\mathrm{Pd} / \mathrm{Ag}$ $(25 \mathrm{wt} \%)(\bullet)$ as function of cycling temperature.

\section{Discussion}

The results of the present study show two glaring features: 1) the mechanical properties of pure palladium are very sensitive to hydrogen absorption/desorption cycling and 2) the mechanical properties of palladium-silver (25 weight\% silver) show virtually no sensitivity to hydrogen absorption/desorption cycling. What may explain this contrast in behavior between palladium and Pd/Ag (25 wt\%)?

The primary factor at play in distinguishing the behavior of pure Pd and Pd/Ag (25 wt\%) may be a subtle but significant difference in the phase behavior of the two metal-hydrogen systems. Figure 18 shows a schematic of the temperature-composition phase diagrams for the palladium-hydrogen (protium) system, the Pd/Ag (15 wt\%)hydrogen system, and the $\mathrm{Pd} / \mathrm{Ag}$ (25 wt\%)-hydrogen system. In these phase diagrams, the $\alpha$ phase is a dilute hydrogen-in-metal solid solution and the $\beta$ phase is a hydrogen rich solid solution hydride phase. Both the $\alpha$ and $\beta$ phases are face-centered cubic (FCC) structures but due to its larger hydrogen content, the $\beta$ phase is an expanded FCC structure compared to the $\alpha$ phase. The two phases are separated by an $(\alpha+\beta)$ coexistence region referred to as a miscibility gap. Passage through the miscibility gap during absorption results in the matrix undergoing the $\alpha \rightarrow \beta$ transition while passage during desorption results in the matrix undergoing the $\beta \rightarrow \alpha$ transition. As can be seen, the width of the miscibility gap decreases as the temperature increases until the critical temperature $\left(\mathrm{T}_{\mathrm{c}}\right)$ of the miscibility gap is reached. At temperatures below $\mathrm{T}_{\mathrm{c}}$ the $\alpha \rightarrow \beta$ and $\beta \rightarrow \alpha$ transitions will occur in a discontinuous fashion owing to the significant volume difference between the $\alpha$ and $\beta$ phases. Once the cycling temperature is above the $\mathrm{T}_{\mathrm{c}}$ of the miscibility gap, the discontinuous $\alpha \rightarrow \beta$ (or $\beta \rightarrow \alpha$ ) transition is replaced by a continuous homogeneous transition between the two phases.

As the schematic indicates, the width of the miscibility gap for the Pd/Ag (25 wt\%)-hydrogen system is significantly smaller than that for the Pd-hydrogen system. Also, the critical temperature for the Pd/Ag (25 wt\%)hydrogen system is significantly lower than that for the Pd-hydrogen system. These findings are a manifestation of the more general observation that as the percent silver in palladium-silver alloys increases, the width of the alloy-hydrogen miscibility gap decreases and the critical temperature of the miscibility gap is lowered [17]. This trend is further illustrated in Figure 18 with the inclusion of the miscibility gap for Pd/Ag (15 wt\%) and more fully illustrated in Table 2 which shows the critical temperatures, lattice constants for the limiting compositions of the $\alpha$ and $\beta$ phases at $298 \mathrm{~K}$, and the percent volume change due to the $\alpha \rightarrow \beta$ (or $\beta \rightarrow \alpha$ ) transition at $298 \mathrm{~K}$ for pure Pd and several Pd/Ag alloys, including Pd/Ag (25 wt\%) [17].

To illustrate what happens to the Pd matrix during hydrogen absorption/desorption cycling at temperatures below $\mathrm{T}_{c}$, consider the following. At $298 \mathrm{~K}$, the miscibility gap in the Pd-H system separates the dilute hydrogen-in-metal $\alpha$ solid solution with a lattice constant of $0.389 \mathrm{~nm}$ and the hydrogen rich $\beta$ hydride phase with a lattice constant of $0.403 \mathrm{~nm}$ [18]. This difference in lattice constants of the two phases results in a volume change in the metal matrix of $\sim 11 \%$ when the $\alpha \rightarrow \beta$ (or $\beta \rightarrow \alpha$ ) transition occurs at $298 \mathrm{~K}$. This abrupt volume change due to the conversion between a dilute solid solution phase and a hydride phase by means of traversing a two-phase region results in the generation of a significant amount of dislocations in the metal matrix [19] [20]. 


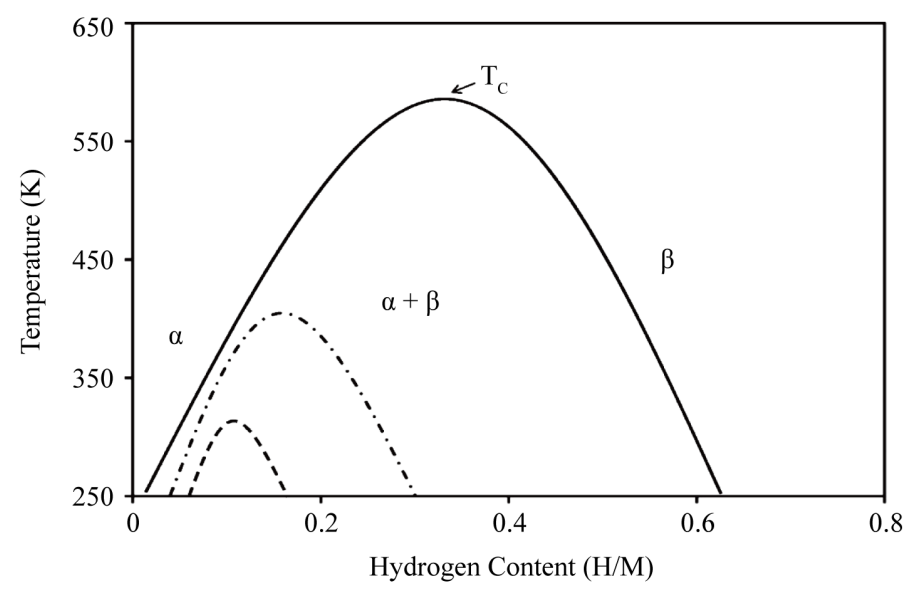

Figure 18. Temperature-composition phase diagram of the palladium-hydrogen system (solid line), Pd/Ag (25 wt\%) (dashed line).

Table 2. Miscibility gap parameters for Pd/Ag-hydrogen systems (based on data in [17]).

\begin{tabular}{ccccc}
\hline Alloy & $\mathrm{T}_{\mathrm{c}}(\mathrm{K})$ & $\begin{array}{c}\alpha \text { lattice constant } \\
\text { @ 298K (nm) }\end{array}$ & $\begin{array}{c}\beta \text { lattice constant } \\
\text { @ 298K (nm) }\end{array}$ & $\begin{array}{c}\text { (nolume } \\
\alpha \rightarrow \beta\end{array}$ (\%) \\
\hline Pure Pd & 570 & 0.389 & 0.403 & 10.9 \\
Pd/Ag (5 wt\%) & 515 & 0.391 & 0.402 & 8.7 \\
Pd/Ag (10 wt\%) & 451 & 0.392 & 0.401 & 7.1 \\
Pd/Ag (15 wt\%) & 400 & 0.393 & 0.400 & 5.4 \\
Pd/Ag (20 wt\%) & 348 & 0.395 & 0.398 & 2.3 \\
Pd/Ag (25 wt\%) & 290 & -- & -- & -- \\
\hline
\end{tabular}

Studies have shown that increased dislocation densities in metals result in increased strength and hardness along with decreased ductility [21]. The present results for Pd are consistent with this situation.

As expected, the amount of dislocations generated in the Pd matrix will depend on the particular parameter being varied. For example, for those Pd samples that partially traversed the miscibility gap (i.e. sections 3.2 and 3.3 of the Results), only a fraction (dictated by the Lever Rule) of the Pd matrix experiences the abrupt volume change between the dilute $\alpha$ phase and the $\beta$ hydride phase. Thus the Pd matrix is expected to have a smaller number of dislocations introduced into it, the smaller the degree to which the miscibility gap is traversed. Because of the smaller dislocation density in a partially cycled matrix, the increases in strength and hardness, along with the decrease in elongation (relative to a vacuum-annealed matrix) should not be as pronounced as in a fully cycled matrix. Our results are in line with this expectation. The width of the miscibility gap for the Pd-deuterium system is slightly less than that of the Pd-protium system [11] and this explains the subtle differences in results found for partially cycled Pd-D (section 3.3) versus partially cycled Pd-H (section 3.2).

The results reported in section 3.4 are also likely dependent on the nature of the miscibility gap in the M-H systems studied. The changes in the mechanical properties of Pd are consistent with significant dislocations being introduced into the Pd matrix during absorption/desorption cycling. But why do the overwhelming majority of the changes occur as a result of the first cycle? Wang et al. have shown via hydrogen solubility measurements and transmission electron microscopy that one cycle of hydride formation and decomposition (i.e. traversal of the $(\alpha+\beta)$ miscibility gap) in palladium does give rise to a significant build-up of dislocations [20]. However, they also found that additional hydride formation/decomposition cycling does not lead to a continual buildup of dislocations in the Pd matrix as the number of cycles increases. The overwhelming majority of dislocations are generated during the first cycle of hydride formation/decomposition after which there appears to be an upper limit of dislocations reached after only a few additional cycles of hydride formation and decomposition. The explanation given is that dislocations continue to be generated during each cycle through the $(\alpha+\beta)$ miscibility 
gap but they are offset by a concomitant annihilation of existing dislocations in the Pd matrix thus resulting in a steady-state maximum dislocation density in the Pd matrix after only a few cycles. Our results are consistent with the occurrence of a steady-state maximum dislocation density in palladium that has been subjected to multiple traversals through the $(\alpha+\beta)$ miscibility gap.

The decrease in the width of the Pd-H miscibility gap as temperature increases explains the results found in section 3.5. As temperature increases, the width of the Pd-H miscibility gap decreases and the difference in lattice constants between the $\alpha$ phase and the $\beta$ phase decreases. This results in a decrease in the volume difference between the $\alpha$ phase and the $\beta$ phase as temperature increases until at $\mathrm{T}_{\mathrm{c}}$ (and temperatures above) the discontinuity of the $\alpha \rightarrow \beta$ (or $\beta \rightarrow \alpha$ ) transition is replaced with a continuous transition that does not involve an abrupt volume change. Thus as the temperature increases, the volume change during the $\alpha \rightarrow \beta$ (or $\beta \rightarrow \alpha$ ) transition decreases and the amount of dislocations generated also decreases. The decrease in the dislocation density as the hydrogen exposure temperature increases results in a progressive muting of the increases in strength and hardness along with a similar muting of the decrease in ductility (i.e. a muting of the degree of embrittlement). This behavior is seen in plots of Figures 2-4 for temperatures from $\sim 475 \mathrm{~K}$ to the $(\alpha+\beta)$ critical temperature of $\sim 570$ $\mathrm{K}$. The displayed behavior of the mechanical properties of the Pd-H system outside this temperature range has been explained elsewhere [22].

The findings for Pd/Ag (25 wt\%) can be explained with much greater brevity than those for pure Pd. As indicated in Table 2, the critical temperature for the miscibility gap in the Pd/Ag (25 wt\%)-H system is at $~ 290 \mathrm{~K}$. Thus cycling above $290 \mathrm{~K}$ does not involve passage through the miscibility gap. The $\alpha \rightarrow \beta$ (and $\beta \rightarrow \alpha$ ) transitions in the alloy-H system at all temperatures studied were of a continuous nature and did not involve an abrupt change in volume within portions of the matrix. Without the abrupt and discontinuous volume change, dislocations are not generated to a significant extent. Without the generation of dislocations, the mechanical properties of the alloy matrix will not suffer the effects of hydrogen cycling that pure palladium did.

\section{Conclusions}

Our studies have shown that hydrogen absorption/desorption cycling does result in significant changes to the mechanical properties of well-annealed Pd. In all instances studied, hydrogen absorption/desorption cycling strengthens and hardens Pd while causing embrittlement (loss of elongation). In contrast, we have found that hydrogen absorption/desorption cycling has virtually no effect on the mechanical properties of well-annealed $\mathrm{Pd} / \mathrm{Ag}$ (25 wt\%). Most significantly, under the conditions studied, Pd/Ag (25 wt\%) appears to be impervious to hydrogen embrittlement.

We have provided a plausible explanation for the observed changes in the mechanical properties of palladium and lack of changes to the properties of Pd/Ag (25 wt\%) in terms of the generation of dislocations in the Pd matrix during hydrogen absorption/desorption cycling and the lack of dislocations being generated in the Pd/Ag (25 wt\%) matrix.

Our results indicate that if hydrogen embrittlement is to be minimized in palladium-based systems, great care should be taken to work under conditions that avoid an encounter with the miscibility gap that is present in many such systems.

\section{References}

[1] Flanagan, T., Noh, H., Craft, A. and Andersson, Y. (1995) The Solubility of Hydrogen and Deuterium in Crystalline $\mathrm{Pd}_{9} \mathrm{Si}_{2}$. Journal of Solid State Chemistry, 120, 90-95. http://dx.doi.org/10.1006/jssc.1995.1381

[2] Sartori, S., Cuevas, F., and Latroche, M. (2016) Metal Hydrides Used as Negative Electrodes Materials in Li-Ion Batteries. Applied Physics A, 122, 1-7. http://dx.doi.org/10.1007/s00339-016-9674-X

[3] Reshak, A. (2013) $\mathrm{MgH}_{2}$ and LiH Metal Hydrides Crystals as Novel Hydrogen Storage Material: Electronic Structure and Optical Properties. International Journal of Hydrogen Energy, 38, 11946-11954. http://dx.doi.org/10.1016/j.ijhydene.2013.06.118

[4] Kamazawa, K., Aoki, M., Noritake, T., Miwa, K., Sugiyama, J., Towata, S., Ishikiriyama, M., Callear, S., Jones, M., and David, W. (2013) In-Operando Neutron Diffraction Studies of Transition Metal Hydrogen Storage Materials. Advanced Energy Materials, 3, 39-42. http://dx.doi.org/10.1002/aenm.201200390

[5] Bulak, J., Jimenez, G., Millette, N., Rebeiz, K. and Craft, A. (2007) Stress-Induced Changes to the Triple-Point Phase Boundary of the Niobium-Deuterium System. Journal of Phase Equilibria and Diffusion, 28, 422-429. 
http://dx.doi.org/10.1007/s11669-007-9158-y

[6] Rebeiz, K., Dahlmeyer, J., Garrison, Tr., Garrison, Ty., Darkey, S., Paciulli, D., Talukder, M., Kubic, J., Wald, K., Massicotte, F., Nesbit, S. and Craft, A. (2015) Tensile Properties of a Series of Palladium-Silver Alloys Exposed to Hydrogen. Journal of Energy Engineering, 141, 1-7.

[7] Ross, D. (2006) Hydrogen Storage: The Major Technological Barrier to the Development of Hydrogen Fuel Cell Cars. Vacuum, 80, 1084-1089. http://dx.doi.org/10.1016/j.vacuum.2006.03.030

[8] Mazzucco, A., Voskuilen, T., Waters, E., Pourpoint, T. and Rokuni, M. (2016) Heat Exchanger Selection and Design Analyses for Metal Hydride Heat Pump Systems. International Journal of Hydrogen Energy, 41, 4198-4213. http://dx.doi.org/10.1016/j.ijhydene.2016.01.016

[9] Nayebossadri, S., Speight, J. and Book, D. (2014) Effects of Low Ag Additions on the Hydrogen Permeability of PdCu-Ag Hydrogen Separation Membranes. Journal of Membrane Science, 451, 216-225. http://dx.doi.org/10.1016/j.memsci.2013.10.002

[10] Lynch, S. (2012) Hydrogen Embrittlement Phenomena and Mechanisms. Corrosion Reviews, 30, 105-123. http://dx.doi.org/10.1515/corrrev-2012-0502

[11] Lewis, F. (1967) The Palladium Hydrogen System. Academic Press, London.

[12] Adams, B. and Chen, A. (2011) The Role of Palladium in a Hydrogen Economy. Materials Today, 14, $282-289$. http://dx.doi.org/10.1016/S1369-7021(11)70143-2

[13] Hatlevik, O., Gade, S., Keeling, M., Thoen, P., Davidson, A. and Way, J. (2010) Palladium and Palladium Alloy Membranes for Hydrogen Separation and Production: History, Fabrication Strategies, and Current Performance. Separation and Purification Technology, 73, 59-64. http://dx.doi.org/10.1016/j.seppur.2009.10.020

[14] Jonsen, D. Moss, A., Shenk, J., Rebeiz, K., Nesbit, S., Foley, R. and Craft, A. (1995) Tensile and Fatigue Properties of the Order-Disorder System $\mathrm{Pd}_{3+\mathrm{x}} \mathrm{Mn}_{1-\mathrm{x}}$. Materials Science and Engineering: A, 199, 131-138. http://dx.doi.org/10.1016/0921-5093(94)09699-6

[15] Timofeev, N., Berseneva, F. and Makarov V. (1994) New Palladium-based Membrane Alloys for Separation of Gas mixtures to Generate Ultrapure Hydrogen. International Journal of Hydrogen Energy, 19, 895-898. http://dx.doi.org/10.1016/0360-3199(94)90042-6

[16] Tosti, S., Bettinali, L. and Violante, V. (2000) Rolled Thin Pd and Pd-Ag Membranes for Hydrogen Separation and Production. International Journal of Hydrogen Energy, 25, 319-325. http://dx.doi.org/10.1016/S0360-3199(99)00044-0

[17] Perrot, P., Moelans, N. and Lebrun, N. (2006) Noble Metal Ternary Systems: Phase Diagrams, Crystallographic and Thermodynamic Data, G. Effenberg and S. Ilyenko, Eds. Springer, Berlin.

[18] Krenn, C. (2004) Continuum Modelling of transformation Hysteresis in a Metal Hydride System. Modelling and Simulation in Materials Science and Engineering, 12, S415-S424. http://dx.doi.org/10.1088/0965-0393/12/4/s08

[19] Flanagan, T. and Park, C. (1998) Hydrogen Storage Materials. In: Barnes, R., Ed., Materials Science Forum, Chapter 12, Trans Tech Publications, Aedermannsdorf, 297-305.

[20] Wang, D., Flanagan, T. and Balasubramaniam, B. (1999) Hydrogen Solubility as a Probe for Dislocation Formation, Rearrangement and Annihilation in $\mathrm{Pd}$ and $\mathrm{Pd} / \mathrm{Al}_{2} \mathrm{O}_{3}$ Composites. Scripta Materialia, 41, 517-521. http://dx.doi.org/10.1016/S1359-6462(99)00183-9

[21] Askeland, D. (1984) The Science and Engineering of Materials. PWS-Kent Publishing, Boston.

[22] Jimenez, G., Dillon, E., Miller, R., Massicotte, F., Nesbit, S. and Craft, A. (2008) The Role of Hydrogen-Exposure Temperature on the Mechanical Properties of Hydrogen-Cycled Palladium. Scripta Materialia, 59, 870-874. http://dx.doi.org/10.1016/j.scriptamat.2008.06.031 


\section{Submit or recommend next manuscript to SCIRP and we will provide best service for you:}

Accepting pre-submission inquiries through Email, Facebook, Linkedin, Twitter, etc A wide selection of journals (inclusive of 9 subjects, more than 200 journals)

Providing a 24-hour high-quality service

User-friendly online submission system

Fair and swift peer-review system

Efficient typesetting and proofreading procedure

Display of the result of downloads and visits, as well as the number of cited articles

Maximum dissemination of your research work

Submit your manuscript at: http://papersubmission.scirp.org/ 